\title{
Using Fixed-Wing UAV for Detecting and Mapping the Distribution and Abundance of Penguins on the South Shetlands Islands, Antarctica
}

\author{
Christian Pfeifer ${ }^{1, *(\mathcal{D}}$, Andres Barbosa ${ }^{2}$, Osama Mustafa $^{1}{ }^{1}$, Hans-Ulrich Peter ${ }^{3}$, \\ Marie-Charlott Rümmler ${ }^{1}$ and Alexander Brenning ${ }^{4}$ (D) \\ 1 Thuringian Institute of Sustainability and Climate Protection (ThINK), Leutragraben 1, 07743 Jena, Germany; \\ osama.mustafa@think-jena.de (O.M.); marie-charlott.ruemmler@think-jena.de (M.-C.R.) \\ 2 Department of Evolutionary Ecology, Natural History Museum, CSIC, José Gutiérrez Abascal, 2, \\ 28006 Madrid, Spain; barbosa@mncn.csic.es \\ 3 Institute of Ecology and Evolution, Friedrich Schiller University Jena, Dornburger Straße 159, 07743 Jena, \\ Germany; hans-ulrich.peter@uni-jena.de \\ 4 Department of Geography, Friedrich Schiller University Jena, Löbdergraben 32, 07743 Jena, Germany; \\ alexander.brenning@uni-jena.de \\ * Correspondence: christian.pfeifer@think-jena.de
}

Received: 28 March 2019; Accepted: 17 April 2019; Published: 19 April 2019

\begin{abstract}
Antarctic marine ecosystems undergo enormous changes, presumably due to climate change and fishery. Unmanned aerial vehicles (UAVs) have an unprecedented potential for measuring these changes by mapping indicator species such as penguins even in remote areas. We used a battery-powered fixed-wing UAV to survey colonies along a 30-km stretch of the remote coast of southwest King George Island and northwest Nelson Island (South Shetland Islands, Antarctica) during the austral summer 2016/17. With multiple flights, we covered a total distance of $317 \mathrm{~km}$. We determined the exact position of 14 chinstrap penguin colonies, including two small unknown colonies, with a total abundance of 35,604 adults. To model the number of occupied nests based on the number of adults counted in the UAV imagery we used data derived from terrestrial time-lapse imagery. The comparison with previous studies revealed a decline in the total abundance of occupied nests. However, we also found four chinstrap penguin colonies that have grown since the 1980s against the general trend on the South Shetland Islands. The results proved the suitability of the use of small and lightweight fixed-wing UAVs with electric engines for mapping penguin colonies in remote areas in the Antarctic.
\end{abstract}

Keywords: Antarctica; birds; BVLOS; penguin; drone; fixed-wing UAV; monitoring; population change; Pygoscelis antarcticus; South Shetland Islands

\section{Introduction}

The Antarctic marine ecosystems are currently undergoing enormous changes due to climate change and fishing activities [1,2]. However, determining these changes in remote Antarctic areas is difficult, and therefore, the data availability is sparse. Because of their unprecedented potential for mapping wildlife, Unmanned Aerial Vehicles (UAVs) are promising for measuring these changes e.g., [3-6] by surveying indicator species such as breeding penguins.

Penguins are a key part of the ecosystems of the Southern Ocean and the Antarctic, and their changing population numbers reflect ecosystem changes in the short term $[7,8]$. The general population trend of chinstrap penguins (Pygoscelis antarcticus) is considered to be decreasing, but the spatial pattern is complex, with increasing and decreasing populations in different regions [9]. Therefore, 
this species appears to be a sensitive indicator for spatially differentiated ecosystem changes in the Southern Ocean. However, detailed knowledge of quantitative changes of this species is lacking, not least due to the often very difficult to access breeding habitats. An area where several studies reported a significant decline in chinstrap penguin population over the last 30-40 years [10-12] are the South Shetland Islands.

A key parameter for detecting these changes is the abundance of breeding pairs or occupied nests. While the abundance is easy to determine in colonies with good access (e.g., next to stations) by exact ground counts, many colonies of this species are located in remote areas and rugged terrain. Such an area is the rocky cliff coast of northwest Nelson Island and southwest King George Island (KGI). There is a large number of small islets, rocks and headlands only accessible by inflatable boats that have to navigate over large distances and dangerous currents. Several expeditions in the 1980s explored the northwest coast of Nelson Island e.g., [13,14] and the west coast of KGI [15,16], providing estimates of the chinstrap penguin colony distribution and abundance.

After these explorations, data on the population development in the study region is very sparse. Only very small chinstrap colonies at the western coast of Fildes Peninsula have been observed [17-19]. The first precise abundance data for a penguin colony at northwest Nelson Island was provided just after UAVs were introduced in Antarctica when Withem Island (northwest of Nelson Island) was mapped using a multicopter UAV [20].

Nevertheless, current and reliable information about the distribution and abundance of the chinstrap penguin colonies in the region is needed to detect possible population changes. Of all KGI, only some colonies at the southern and eastern coast have been monitored regularly e.g., [12,21]; it is, therefore, completely unknown whether the strong decline in chinstrap population in the last decades in those colonies is also representative for the west coast. This question is of particular interest, since the chinstrap penguins breeding at the southeast coast are most likely to have different foraging areas during the breeding season than those at the west coast [22].

To census the colonies, previous expeditions used small inflatable boats launched from research vessels e.g., [15] or nearby stations e.g., [14]. Precise ground counts are time-consuming for large colonies, but the available time in the field is limited [20], so most of the previous expeditions were only able to estimate the abundance of the colonies. One option to avoid these restrictions is the use of manned aircraft for aerial photography e.g., [23]. However, this entails considerable logistical efforts and costs. The use of satellite imagery is the most economical option, though it provides much less detailed and precise information, since colony size can only be derived from the extent of the guano cover, which is relatively inaccurate compared to counts of individuals [20,24-27]. Additionally, both methods are severely limited by the frequent cloud cover in this region.

Another method that has been used in the Antarctic is multicopter UAVs [20,28-31], or a heavier and bigger fixed-wing UAV with an internal combustion engine [6,21,32]. UAVs allow counting individual penguins precisely $[4,33]$ with minimal disturbance $[20,34,35]$. However, multicopter UAVs have only a very limited flight range, while the larger fixed-wing UAVs with internal combustion engines have much longer flight ranges, but greater logistical demands [36].

This article presents the first use of a small and lightweight battery-powered fixed-wing UAV for detecting penguin colonies and determining their population size. We chose this type of UAV for its longer flight range compared to multicopters, and its smaller logistical demands compared to the much larger fixed-wing UAVs with internal combustion engines. While the main aim was to detect colonies and count individuals, we also modeled the number of nests based on the UAV derived counts of adults, making them comparable to previous historic counts. Since it is not possible to count nests directly from aerial images [28], we used a ratio describing the relation between the peak number of nests and the number of individuals at the time of the UAV flights using the data of time-lapse cameras. In this way, we were able to identify possible changes in size and distribution of the chinstrap penguin colonies in the study area. 


\section{Materials and Methods}

\subsection{Study Area}

The study area is located at the South Shetland Islands north of the Antarctic Peninsula. It ranges along the west coast of Nelson and King George Island from Smilets Point on Nelson Island in the south to Sygit Point off the coast of King George Island in the north (Figure 1). The cliff coast is characterized by hundreds of islets difficult to reach from nearby stations [37] (Figure 2).

The study area was divided into three subareas, each about $10 \mathrm{~km}$ long (see Figure 1):

- The southern subarea from Smilets Point to Fildes Strait at the glacierized coast of Nelson Island,

- the central subarea from Fildes Strait to Porebski Cove at the glacier-free coast of Fildes Peninsula, and

- the northern subarea from Porebski Cove to Sygit Point at the glacierized coast of King George Island.

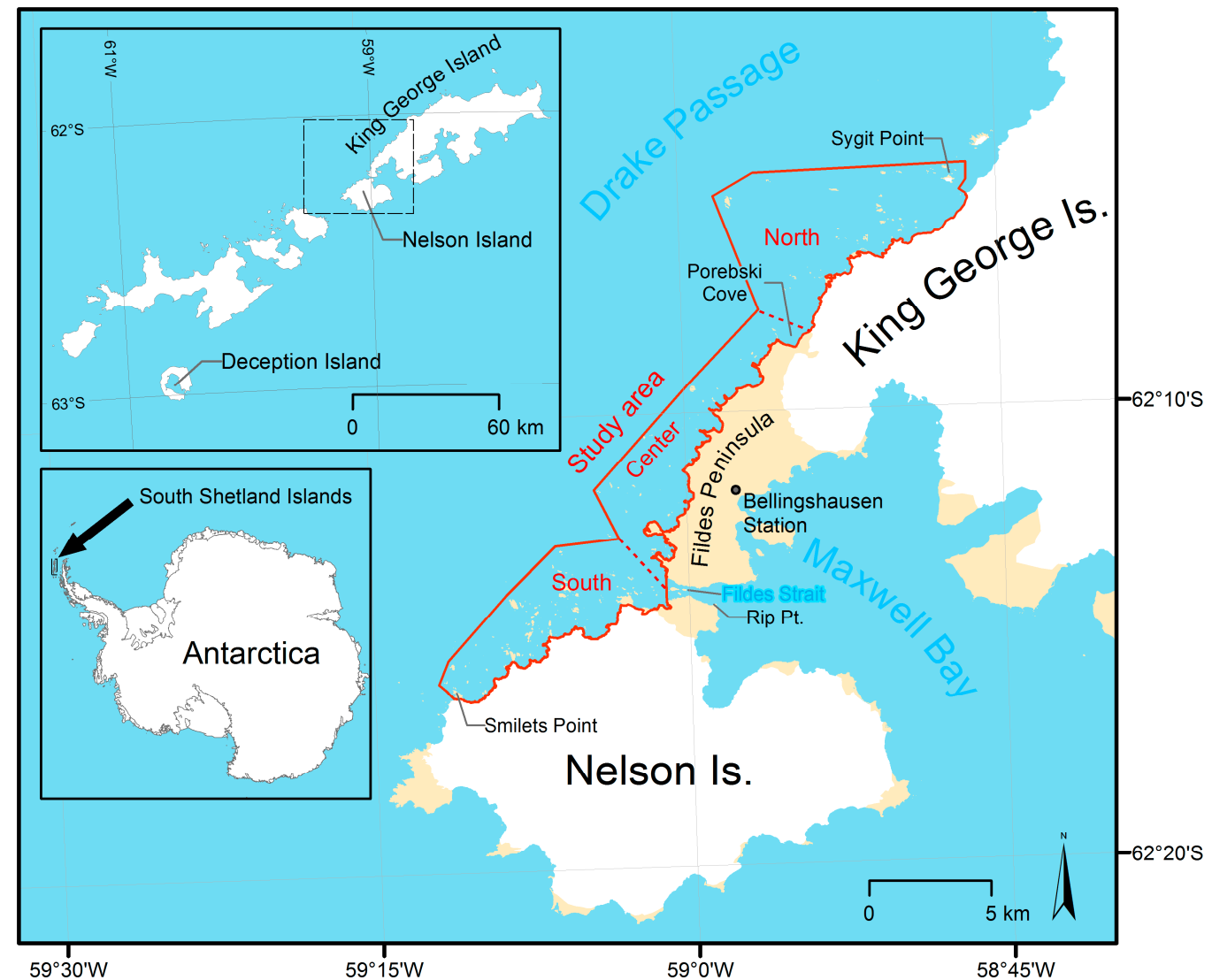

Figure 1. The study area extends for about $30 \mathrm{~km}$ along the coast of northwest Nelson Island and southwest King George Island (South Shetlands Islands, Antarctica) and is divided into three subareas (North, Center, South). Maps created with data from the SCAR Antarctic Digital Database.

To minimize the number of flights, only potential breeding sites were mapped by UAV flights. These are ice-free areas above the supralittoral zone on islands, islets and headlands [38]. To define these sites, a high-resolution Quickbird-2 satellite image (acquisition date: 21 February 2006; id 1010010004D26100) with a ground sampling distance (GSD) of $0.5 \mathrm{~m}$ per pixel and a medium resolution Sentinel-2A image with a GSD of $10 \mathrm{~m}$ per pixel (acquisition date: 2016 January 2018; tile number T21EUM) have been analyzed visually. 


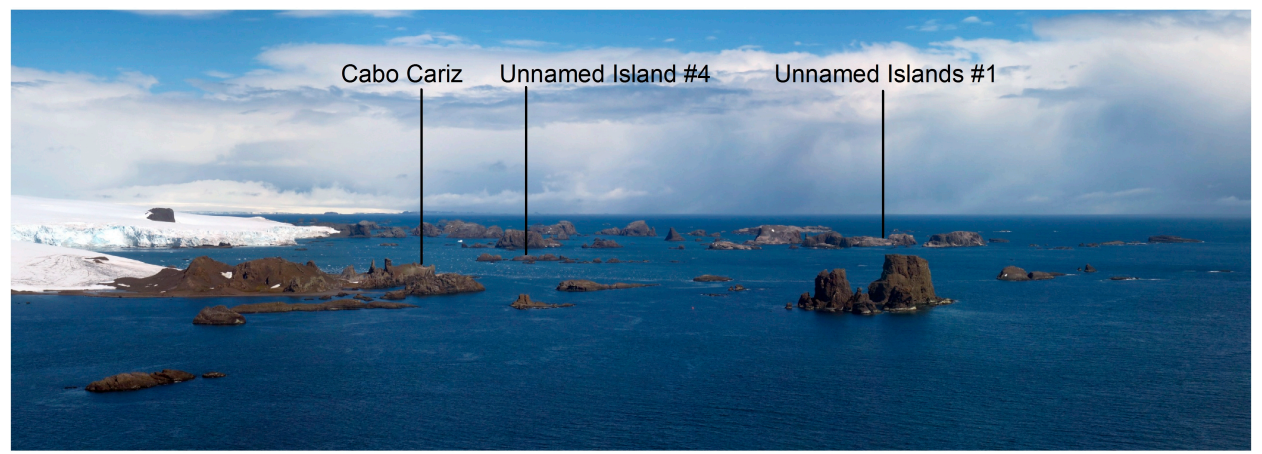

Figure 2. Panorama image of the northwestern coast of Nelson Island showing the typical landscape with numerous islets and rock outcrops along the glacierized coast, including some penguin colonies in the back (photograph taken on 4 January 2017).

\subsection{Ground Survey at Fildes Peninsula}

The potential number of flight days in this region is limited by strong winds, rain and fog [29]. To reduce the number of flights to a necessary minimum, we checked the whole ice-free coast of Fildes Peninsula on the ground for the presence of penguin colonies on 25 December 2016. This ground survey included all inaccessible islets ( $<300 \mathrm{~m}$ from the coast) which could be observed by using binoculars. Because of the good accessibility of the colony at Sehnem Point the number of nests was counted there directly without the necessity of a UAV flight. UAV flights were therefore necessary for the islets further away from the coast and for the colonies that were not accessible by the ground survey.

\subsection{UAV and Camera}

The UAV survey was carried out in December 2016 and the beginning of January 2017. This is during a period of late incubation or early chick-rearing before chinstrap penguin chicks leave the nests and form crèches.

To map the remote offshore islets we used the electrically powered micro tailless delta fixed-wing UAV BORMATEC Ninox (Figure 3). We chose a fixed-wing UAV over the more widely used multicopter technology for its longer flight duration and higher flight speed, which allows it to cover a larger area per flight [39]. Because of the small size, and lightweight and compact design of this model (see Table 1) we were able to launch it by hand from any open space and to land on gravel beaches or flat patches of ice, snow or dirt. The wings and fuselage of the UAV are made of foam (Expanded Polypropylene) making it very durable for landings on rougher ground and allowing fast repair of smaller damages in the field.

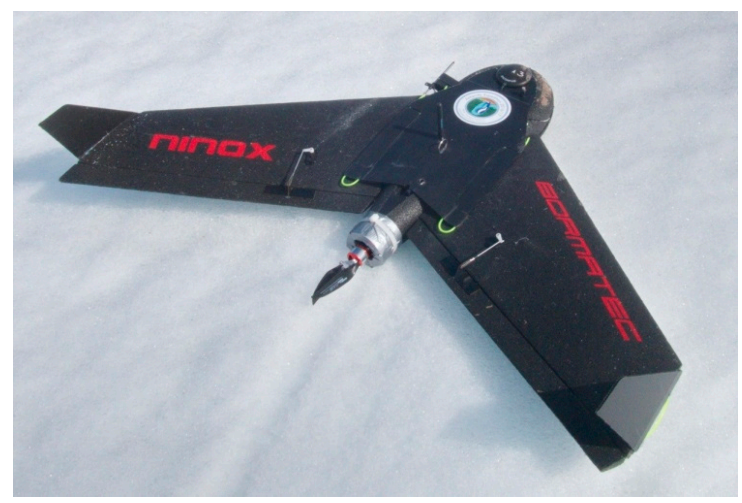

Figure 3. The battery-powered fixed-wing UAV BORMATEC Ninox after landing on a snowfield on King George Island. 
We had to modify the off-the-shelf UAV to carry a camera and perform long-distance flights beyond the visual line of sight (BVLOS) even in windy weather. To maximize the flight range, we equipped the UAV with an additional battery. For better control under harsh weather conditions, we installed an airspeed sensor. For data capture, we used a lightweight (60g) MAPIR Survey-2 RGB digital camera. The camera had a 16 megapixel $(4608 \times 3456$ pixel $)$ CMOS sensor, a lens with $82^{\circ} \mathrm{HFOV}$ and a focal length of $3.97 \mathrm{~mm}$, which results in an image footprint of $155 \times 116 \mathrm{~m}$ at a flight height of $100 \mathrm{~m}$ AGL. All images were taken in manual mode ( $\mathrm{f} / 2.8$, shutter speed $1 / 500 \mathrm{~s}$, ISO 50 ) to prevent under-exposure of the relatively dark rock areas when bright snow cover appears in the image, and to prevent motion blur. Images were taken in JPEG format in 2.5-s intervals using the built-in intervalometer.

Table 1. Basic characteristics of the fixed-wing UAV BORMATEC Ninox as used in this study. Source: own measurements.

\begin{tabular}{|c|c|}
\hline & Parameters \\
\hline Size (in flight mode) & $1.0 \mathrm{~m}$ wingspan, $0.64 \mathrm{~m}$ length \\
\hline Take-off weight of the modified UAV & $1 \mathrm{~kg}$ \\
\hline Motor/Propellers & $160 \mathrm{~W}$ brushless motor with $8 \times 4.5^{\prime \prime}$ folding propellers \\
\hline Batteries & $2 \times 3 S 2200 \mathrm{mAh}$ lithium polymer \\
\hline Autopilot & Pixhawk 1 \\
\hline GNSS & uBlox Neo M8N module (GPS \& GLONASS were used) \\
\hline Telemetry & $\begin{array}{c}\text { SiK Telemetry Radio, max. } 100 \mathrm{~mW} \text { output power, } 433 \mathrm{MHz} \text { band } \\
\text { with an omnidirectional antenna }\end{array}$ \\
\hline Electronic speed control (ESC) & $\max .25 \mathrm{~A}$ \\
\hline Additional sensors & $\begin{array}{l}\text { Pixhawk digital differential airspeed sensor (4525DO) } \\
\text { MAPIR Survey-2 RGB digital camera }\end{array}$ \\
\hline
\end{tabular}

During flights, the UAV was controlled completely autonomously by the Pixhawk 1 flight computer, which allowed flights beyond the range of the onboard receivers $(<500 \mathrm{~m})$ and beyond the visual line of sight. Flights were programmed preflight using the ground control station application Mission Planner (v. 1.3.40), which supports custom-made offline maps. These offline maps included the most accurate available contour lines, satellite images or scanned maps of the survey region. At the time of the survey, there were no precise digital surface models available for Nelson Island and most of the small islands along the coast of Nelson and King George Island. Flight paths were planned so that the images would have an overlap of $70 \%$ in the flight direction and, if necessary, also $70 \%$ between the flight paths. The flight height was planned to range from 70 to $100 \mathrm{~m}$ AGL resulting in a ground resolution of 24 to $34 \mathrm{~mm}$ per pixel.

The UAV was also easy to transport because of its compact size, and could be carried, strapped to a backpack, by one person for hours. This made it possible to operate the UAV from various points at Fildes Peninsula that were closest to the predicted penguin colonies, and thus remotely from stations. In consequence, the area covered by the UAV could be substantially increased in comparison to a fixed start/landing point e.g., at an airfield.

At the time of the survey there were no general restrictions regarding flights beyond the visual line of sight in Antarctica, although all UAV operations for scientific purpose are strictly regulated and have to go through an Environmental Impact Assessment by the responsible national authority (based on the Antarctic Treaty Consultative Meeting Resolution 4-2018). Additionally, on-site permission was obtained from air traffic control before conducting flights within a $1.5 \mathrm{~km}$ distance from the Fildes Peninsula airport and a co-pilot was spotting for aircraft during the flight.

\subsection{Geotagging and Orthorectification}

The images obtained by the onboard camera during the flight were stitched to orthomosaics (UTM 21E/WGS84) for every potential breeding site. For this step, we geotagged the single images with the software ExifTool (v.10.36) using the flight logs (GPX format; no GNSS post-processing computation was performed) of the UAV and the time of the image acquisition recorded as Exif tags in the images. Orthomosaics were created using these geotagged images and the photogrammetric image processing 
software Agisoft Photoscan Pro, which implements the Structure from Motion (SfM) technique e.g., [40]. There were no ground control points available in the study area for correcting the absolute positional accuracy. With the help of 14 ground control points in the vicinity of the Bellingshausen Station (see Figure 1), which were mapped using the same UAV, a root-mean-square error of $8.34 \mathrm{~m}(\mathrm{XYZ})$ was obtained.

\subsection{Counts of Individual Adults in the Orthomosaics}

All 193 orthomosaics were manually screened for signs of bird colonies such as visible individuals or reddish guano cover [41-43]. If a penguin colony was found, only adults in guano-covered areas were counted, not including adults staying at or below the supralittoral zone or adults walking towards the breeding groups (Figure 4).

We identified the guano-covered areas in the supralittoral zone based on the elevation $(<5 \mathrm{~m}$ above sea level) with the help of the UAV derived digital surface models, the location (close to the shoreline), and the guano color (whitish). Counting occupied penguin nests instead of individual adults was not possible as the occupied nests of the three Pygoscelid species are not clearly recognizable in the images [44]. For counting, we used QGIS (v.2.18.4). Each individual was marked with a point in an ESRI shapefile to avoid double counting and gaps.

We conceptually distinguish between breeding sites, colonies, subcolonies, and breeding groups (Table 2), and report penguin counts at the colony and subcolony levels. Using these definitions, the breeding penguins at the site Rzepecki Islands, for example, are part of one large colony with one subcolony at each of the three islands, which are at most $450 \mathrm{~m}$ apart from each other.

Because of the possible confounding of penguins with rocks or cast shadows we estimated the precision of the counts. For this purpose, three additional observers counted the adults in an area representing $9 \%$ of the total number of adults and compared the results with those of the main observer. All observers had prior experience in UAV image interpretation of penguin colonies.

Table 2. Definitions used in this study to describe occurrences of breeding penguins.

\begin{tabular}{cc}
\hline Category & Description \\
\hline Breeding group & Occupied nests with a distance $<2 \mathrm{~m}$ \\
Subcolony & Breeding groups with a distance $<50 \mathrm{~m}$ \\
Colony & Subcolonies with a distance $<500 \mathrm{~m}$ \\
Breeding site & Topographically distinct (ice-free) areas with recent and/or historic colonies \\
\hline
\end{tabular}

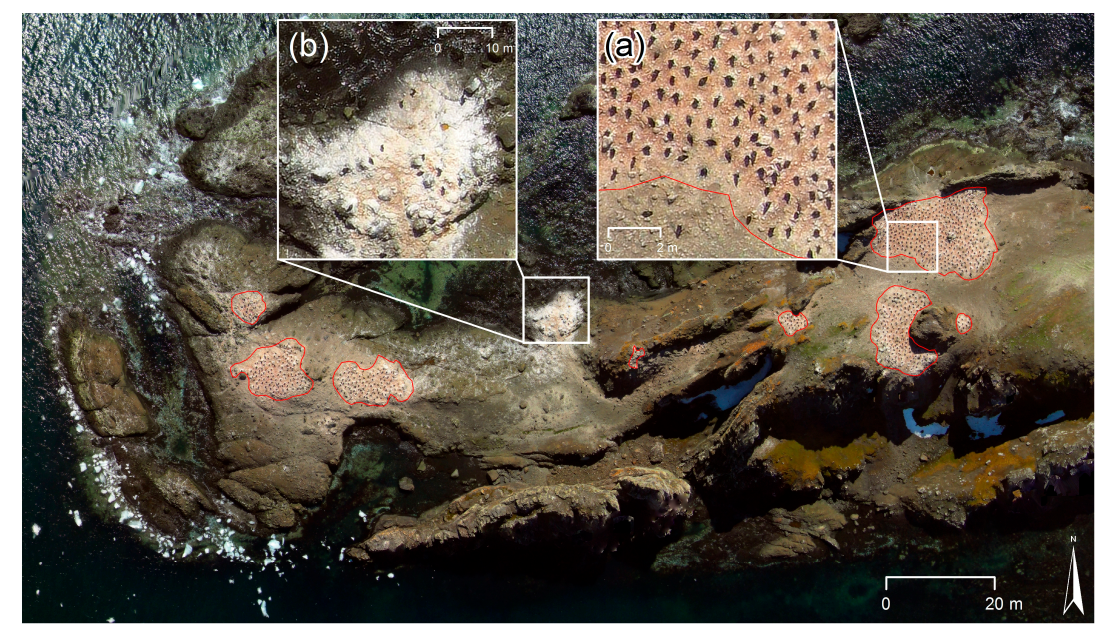

Figure 4. UAV orthomosaic of the chinstrap penguin (Pygoscelis antarcticus) colony at Cabo Cariz (Nelson Island): (a) showing the guano-covered areas with occupied nests (red polygons) where individuals were counted, and (b) an area in the sublittoral zone close to the shoreline with no occupied nests where individuals were not counted. 


\subsection{Modeling Breeding Pair Numbers of UAV-Based Counts}

\subsubsection{Estimating the Number of Nests}

The standard unit to quantify the size of a penguin colony is the number of breeding pairs or occupied nests (further referred to as nests [44]). However, in UAV imagery only individuals are reliably detectable [44]. Due to non-breeders, failed breeders staying in the colony, or individuals returning from foraging trips, the number of adults in a penguin colony differs from the number of occupied nests or breeding pairs. The number of adults and the number of occupied nests furthermore change within a breeding season and over the course of a day, which further complicates abundance estimation of nests [44-46]. It was therefore necessary to apply adjustment procedures.

To determine the number of nests $\hat{N}$ in the study area in 2016/17, we analyzed data from time-lapse cameras cf. $[47,48]$. To obtain the ratio $r(t)$, describing the relation between the (peak) number of nests $n$ one week after the peak of egg-laying (PoE) [49] and the number of adult individuals $a(t)$ at a given time $t$ :

$$
r(t)=\frac{n}{a(t)}
$$

This ratio can be used to estimate the number of nests in the study area, $\hat{N}$, based on UAV-derived adult individuals counts $A(t)$, while accounting for the shift in breeding phenology, $\Delta t$, between both areas:

$$
\hat{N}=r(t-\Delta t) A(t)
$$

The outlined approach was implemented as follows:

- We used time series of two time-lapse cameras at the Vapour Col colony $\left(62.9912^{\circ} \mathrm{S}, 60.7201^{\circ}\right.$ W [50]) on Deception Island (South Shetland Islands; about 100 km southwest of Nelson Island) showing overviews of chinstrap nest groups. For the analysis, three images per day (01 Dec 2016 to 10 Jan 2017 at 11:00, 13:00 and 15:00 UTC-3h) were selected, since all UAV flights took place around these times (see Table 4). The number of adults was counted within a fixed area in every image, and the mean of the counts from both cameras, $a(t)$, was calculated, yielding up to three daily values for 32 days with good visibility for a total of 93 values of $a(t)$. We averaged all three daily values, since we found no systematic differences in the number of adults between these time points.

- We further determined the number of occupied nests, $n$, one week after the peak of egg-laying (CCAMLR [51] Part I, Section 1: Method A3A) in the same area. The adults were counted using time-lapse imagery from 19 Nov 2016, which is one week after the local PoE (12 November 2016 [52]). For the standardization, we calculated the nest-to-individual ratio $r(t)$ from the camera-derived $n$ and $a(t)$.

- A generalized additive model (GAM [53]) was used to model the (possibly nonlinear) temporal changes in the ratio $r(t)$. This allowed us to remove random variability and close gaps in the camera-derived time series that were caused by unusable or missing imagery (e.g., due to fog or camera malfunctioning). We used the software R (v.3.2.3) and its mgcv package [54]. The 95\% prediction intervals of the predicted $r(t)$ were used to represent and propagate uncertainties.

- The regional time shift $\Delta t$ in breeding phenology between camera and UAV sites was determined based on data from Hinke et al. [52], who reported that the PoE of chinstrap penguins in the 2016/17 season on KGI (colony Patelnia, 22 November 2016) took place three days later than on Deception Island (Vapour Col, 19 November 2016).

\subsubsection{Accuracy Assessment of the Model}

Since we had no ground truth data for season 2016/17, we estimated the model accuracy with data from season 2017/18. As the dates of the PoE for the colonies at Deception Island and KGI in season 2017/18 were unknown, we estimated the PoE using a modified model of Lynch et al. [46]. 
For modification, we did not include the adjustment for the geographic latitude of the colony location as recent data about chinstrap phenology $[52,55]$ suggested that clutch initiation dates are not delayed with increasing latitude between colonies of the South Shetland Islands. The data we used for the accuracy assessment were:

- Ground counts of 233 nests on Unnamed Islands \#1 taken on 2 Jan 2018 around noon (about half an hour after the UAV flight)

- $\quad \mathrm{UAV}$-derived counts of adults $A(t)$ covering the area of the ground counts

- The number of adults $a(t)$ counted in the imagery of two time-lapse cameras of the Vapour Col colony (Deception Island) at the time of the UAV and ground surveys. There was no information on differences in breeding phenology $\Delta t$; a correction was therefore not applied.

- The number of occupied nests $n$ visible in time-lapse imagery of the Vapour Col colony taken one week after the local PoE (24 November 2017).

The number of breeding pairs was calculated using the procedure described above, and the deviation of the estimated breeding pair numbers was determined using the ground counts as a reference.

\subsection{Change in Abundance and Distribution}

We compiled a time series of penguin abundance from all academic peer-reviewed and grey literature available to us. This includes unpublished field reports of the German participants of Soviet Antarctic Expeditions to King George Island (e.g., field reports of Erfurt and Grimm [56], Mönke and Bick [57]).

\subsubsection{Determination of Colony Locations of Previous Surveys}

One of the main challenges was the inaccurate location information of the colonies given in earlier studies which made it difficult to match those with the current colony location presented in this study. In particular, three of the breeding sites located along the coast of northwest Nelson Island are unnamed. Some of the colonies in that area could therefore only be located based on their relative position and their relative size in comparison to other colonies. In cases where only the name of the site was given, we used the SCAR Composite Gazetteer of Antarctica to locate them. If maps of the colony locations had been published e.g., [14,16], we used them for geolocating the colonies, too. The scanned maps were georeferenced based on the coastline and compared with the locations of the current breeding sites.

\subsubsection{Modeling the Number of Nests of Previous Surveys}

For two colonies in the northwestern part of Nelson Island, the most precise and complete data we could find was from the survey of Shuford and Spear [16] in 1984/85. Nevertheless, a comparison with our survey data is difficult since they counted adult individuals in February while our survey took place mainly in December. As mentioned previously (see Section 2.6), it is difficult to compare counts that took place at different dates due to intra-seasonal variation. To be able to compare both counts, we estimated the number of nests $\hat{N}$ for the counts of adults from Shuford and Spear [16] using Equations (1) and (2). The ratio of the peak number of nests and adults $r(t)$ was calculated from the 2016/17 time series of the time-lapse cameras of chinstrap penguins from Deception Island. For the estimation of the number of nests, $\hat{N}$, we used the following data:

- The mean of the range of the number of adults $A(t)$ given by Shuford and Spear [16]

- The maximum number of occupied nests $n$ visible in time-lapse imagery of the Vapour Col colony (Deception Island) taken one week after the local PoE (12 November 2016; [52]). 
- The number of adults $a(t)$ counted in the imagery taken at noon (the exact time of the historic ground counts are unknown) of two time-lapse cameras of the Vapour Col colony at 20 Jan 2016 which is 69 days after the local PoE. We used 69 days because this is the period between the PoE and the counts in season 1984/85 by Shuford and Spear [16]. We estimated the date of the PoE in season 1984/85 using the modified model of Lynch et al. [46] (see Section 2.6).

A correction for nest attrition [46] was not applied for the studies that counted occupied nests because the dates of the counts were not given e.g., [15]. To estimate the magnitude of the resulting uncertainties we measured the nest attrition from the PoE (12 November 2017) until the mean crèche (21 January 2017) using the time series of 2016/17 from the time-lapse cameras at Deception Island.

\subsubsection{Estimating the Change Including Uncertainty of Counts}

Most of the reported historical counts, particularly those for northwest Nelson Island, were only based on estimates that lacked information on their accuracy. We therefore decided to make quantitative comparisons to our results only where the accuracy was indicated or where it could be inferred based on our knowledge of the methods used. To indicate the accuracy of the different counts we applied a factor $F$ based on the scheme of Woehler [58] (see Table 3).

Table 3. The accuracy of the previous counts has been classified using the scheme of the census compilation of Woehler [58] and the factor $F$ of inferred uncertainty used for the comparison with our counts. Counts based on: A-adults; N-nests; C-chicks.

\begin{tabular}{cc}
\hline Base of Counts and Accuracy & Inferred Uncertainty \\
\hline A1, N1, C1 $( \pm 0$ to $5 \%)$ & 0.05 \\
A2, N2, C2 $( \pm 5$ to $10 \%)$ & 0.1 \\
A3, N3, C3 $( \pm 10$ to $25 \%)$ & 0.25 \\
A4, N4, C4 $( \pm 25$ to $50 \%)$ & 0.5 \\
A5, N5, C5 (nearest order of magnitude) & - \\
\hline
\end{tabular}

We estimated changes using the published [14,15] or modeled number of nests [16] of the previous counts $B\left(t_{1}\right)$ and the modeled number of nests of this survey $B\left(t_{2}\right)$. Based on historical information, the inferred margin of error $M E\left(t_{1}\right)$ of the number of nests is

$$
M E\left(t_{1}\right)=F\left(t_{1}\right) B\left(t_{1}\right)
$$

while for $t_{2}$, our modeling approach directly gives us a margin of prediction error $M E\left(t_{2}\right)$ at the $95 \%$ confidence level. We combine these to estimate a plausible, but most likely conservative, margin of error for the change in the number of nests.

We use this information to calculate rough, but plausible lower and upper limits for the change in the number of nests,

$$
\begin{aligned}
& \text { lower limit: } \frac{B\left(t_{2}\right)-M E\left(t_{2}\right)}{B\left(t_{1}\right)+M E\left(t_{1}\right)} \\
& \text { upper limit: } \frac{B\left(t_{2}\right)+M E\left(t_{2}\right)}{B\left(t_{1}\right)-M E\left(t_{1}\right)}
\end{aligned}
$$

We consider uncertainty ranges that do not include the value zero as strong evidence of change, although we acknowledge that this is not a rigorous statistical test due to the use of inferred uncertainties for historical counts. 


\section{Results}

\subsection{UAV Survey}

During the five-day survey, we were able to conduct 16 flights (Figure 5). Two flights had to be repeated because a flight height was chosen that was too low on two small islands without elevation data, which resulted in insufficient image overlap. This mistake could be detected and accounted for, since photogrammetric image preprocessing took place on the same day as the flights.

Altogether, the UAV covered a flight distance of $317 \mathrm{~km}$ with an average of $19.8 \mathrm{~km}$ per flight (total coverage included in Supplementary Material S1). An area of 2585 ha with more than 300 islets, islands or headlands was mapped with the onboard digital camera. Around 500-1000 images in JPEG format were collected per flight. With sufficient batteries for five flights, we were able fly up to about $100 \mathrm{~km}$ per day (e.g., 11 December 2016 and 28 December 2016) and cover an area of up to $10 \mathrm{~km}^{2}$.

Flights could not be conducted when there was fog, low clouds $(<100 \mathrm{~m})$, rain or an average wind speed higher than six meter per seconds, which was the most frequent limiting factor. Surprisingly flights during snowfall were successful, and image quality was sufficient. We were able to repair minor damage, which occurred during landings on stony ground, using a mobile hot glue gun in the field. Most of the flights extended beyond the line of sight and went up to five kilometers offshore (Atherton Islands) and up to $10 \mathrm{~km}$ linear distance (Sygit Point) from the starting point. Flight times ranged from 30 to $42 \mathrm{~min}$.

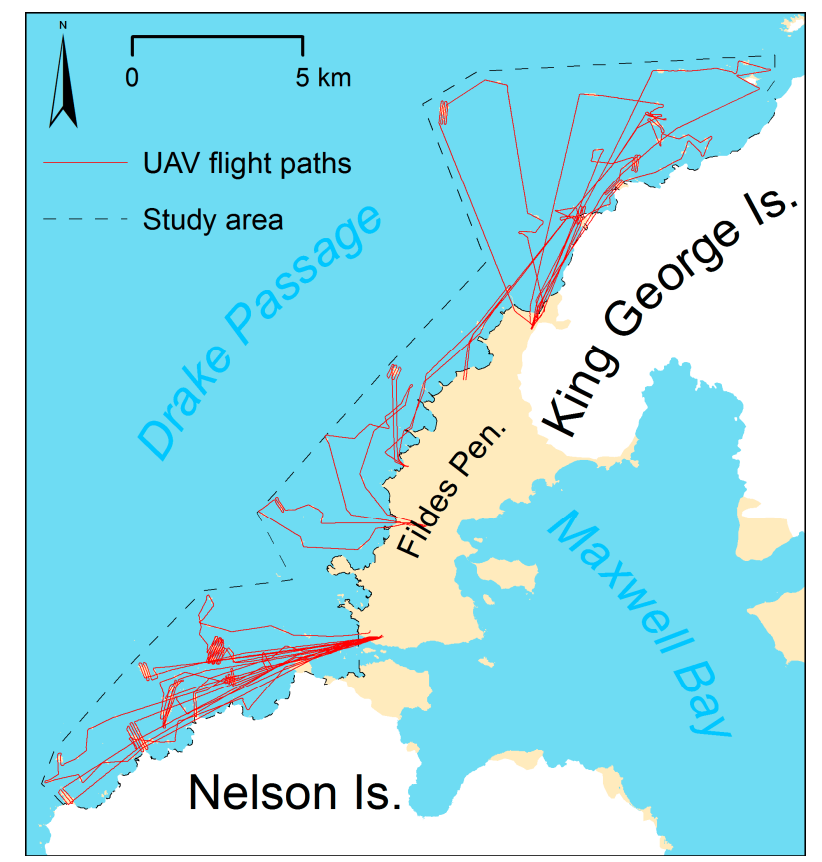

Figure 5. Flight paths of all 16 flights.

\subsection{Abundance and Distribution}

We identified 14 penguin colonies along the coast between Smilets Point on Nelson Island and Sygit Point on KGI with a total of 35,604 adult penguins in December 2016 to January 2017. The repeated counts of four different image observers had a standard deviation of 62 adults, which is equivalent to $1.9 \%$ of the 3211 adults identified in this test area on average. This corresponds to an estimated area-wide standard deviation of 661 adults. We also identified the position (absolute positional accuracy is probably $<10 \mathrm{~m}$ [59]) of all penguin colonies and subcolonies in the study area (Figure 6, Table 4). These, as well as polygons representing the groups of individual penguins in guano-covered areas, are included in Supplementary Materials S3. 
Table 4. Number of adults and modeled number of nests with the margin of error (ME) at the $95 \%$ confidence level for all colonies and subcolonies in the study area.

\begin{tabular}{|c|c|c|c|c|c|c|c|c|}
\hline \multirow[t]{2}{*}{ Sub-Area } & \multirow[t]{2}{*}{ Site } & \multirow{2}{*}{\multicolumn{2}{|c|}{$\begin{array}{c}\text { Number of Adults } \\
\text { Sub-Colony Colony }\end{array}$}} & \multicolumn{2}{|c|}{$\begin{array}{l}\text { Modeled Number of } \\
\text { Nests } \pm \text { ME }\end{array}$} & \multirow{2}{*}{$\begin{array}{c}\text { Survey Date/ } \\
\text { Time (UTC-3h) }\end{array}$} & \multirow[t]{2}{*}{ Lat. } & \multirow[t]{2}{*}{ Lon. } \\
\hline & & & & Sub-Colony & Colony & & & \\
\hline \multirow{10}{*}{ North } & Zawadzki Stacks & - & 83 & - & $68 \pm 4$ & 28 Dec 2016/14:34 & -62.0815 & -58.8388 \\
\hline & & 2486 & & $2046 \pm 126$ & & & -62.0995 & -58.8394 \\
\hline & Rzepecki Islands & 3327 & 8703 & $2738 \pm 168$ & $7162 \pm 440$ & 28 Dec $2016 / 13: 28$ & -62.0951 & -58.8417 \\
\hline & & 2890 & & $2378 \pm 146$ & & & -62.0934 & -58.8416 \\
\hline & & 807 & & $664 \pm 41$ & & & -62.1054 & -58.8546 \\
\hline & Bell Point & 5 & 869 & $4 \pm 0$ & $715 \pm 44$ & 28 Dec 2016/11:49 & -62.1071 & -58.8592 \\
\hline & & 57 & & $47 \pm 3$ & & & -62.106 & -58.8594 \\
\hline & & 85 & & $70 \pm 4$ & & & -62.1188 & -58.8887 \\
\hline & Kwarecki Point & 46 & 136 & $38 \pm 2$ & $112 \pm 6$ & 28 Dec 2016/11:59 & -62.119 & -58.891 \\
\hline & & 5 & & $4 \pm 0$ & & & -62.1187 & -58.8861 \\
\hline \multirow{3}{*}{ Center } & Porebski Cove & - & 61 & - & $50 \pm 3$ & 28 Dec 2016/12:19 & -62.1415 & -58.9254 \\
\hline & Walbucht & - & 155 & - & $131 \pm 7$ & 12 Dec 2016/12:54 & -62.1625 & -58.9773 \\
\hline & Sehnem Point & - & - & - & $48^{1}$ & 15 Dec 2016 & -62.174 & -58.9877 \\
\hline \multirow{15}{*}{ South } & \multirow{7}{*}{ Unnamed Islands \#1 } & 1460 & \multirow{7}{*}{11,959} & $1145 \pm 70$ & \multirow{7}{*}{$9376 \pm 569$} & \multirow{7}{*}{20 Dec 2016/11:07 } & -62.2330 & -59.0889 \\
\hline & & 26 & & $20 \pm 1$ & & & -62.2307 & -59.0900 \\
\hline & & 5625 & & $4410 \pm 268$ & & & -62.2304 & -59.0985 \\
\hline & & 145 & & $114 \pm 7$ & & & -62.2311 & -59.0928 \\
\hline & & 136 & & $107 \pm 6$ & & & -62.2308 & -59.1024 \\
\hline & & 1370 & & $1074 \pm 65$ & & & -62.2280 & -59.0984 \\
\hline & & 3197 & & $2506 \pm 152$ & & & -62.2329 & -59.1010 \\
\hline & Unnamed Island \#4 & - & $41^{2}$ & - & $35 \pm 2$ & 11 Dec 2016/14:11 & -62.2354 & -59.0709 \\
\hline & Cabo Cariz & - & 935 & - & $791 \pm 48$ & 04 Jan 2017/15:04 & -62.2343 & -59.0563 \\
\hline & Unnamed Island \#3 & - & $63^{2}$ & - & $53 \pm 3$ & 04 Jan 2017/12:42 & -62.2433 & -59.1279 \\
\hline & \multirow{3}{*}{ Unnamed Island \#2 } & 408 & \multirow{3}{*}{444} & $352 \pm 19$ & \multirow{3}{*}{$383 \pm 21$} & \multirow{3}{*}{11 Dec 2016/14:09 } & -62.2375 & -59.0902 \\
\hline & & 7 & & $6 \pm 0$ & & & -62.2385 & -59.0914 \\
\hline & & 29 & & $25 \pm 1$ & & & -62.2391 & -59.0881 \\
\hline & Withem Island & $\begin{array}{c}10,921 \\
86\end{array}$ & 11,007 & $\begin{array}{c}9409 \pm 520 \\
74 \pm 4\end{array}$ & $9483 \pm 524$ & 11 Dec 2016/12:24 & $\begin{array}{l}-62.2356 \\
-62.2355\end{array}$ & $\begin{array}{l}-59.1392 \\
-59.1335 \\
\end{array}$ \\
\hline & Smilets Point & $\begin{array}{l}570 \\
578\end{array}$ & 1148 & $\begin{array}{l}491 \pm 27 \\
498 \pm 28\end{array}$ & $989 \pm 55$ & 11 Dec 2016/15:06 & $\begin{array}{l}-62.2667 \\
-62.2685\end{array}$ & $\begin{array}{l}-59.1878 \\
-59.1863\end{array}$ \\
\hline
\end{tabular}

${ }^{1}$ Ground count of nests. ${ }^{2}$ First record.

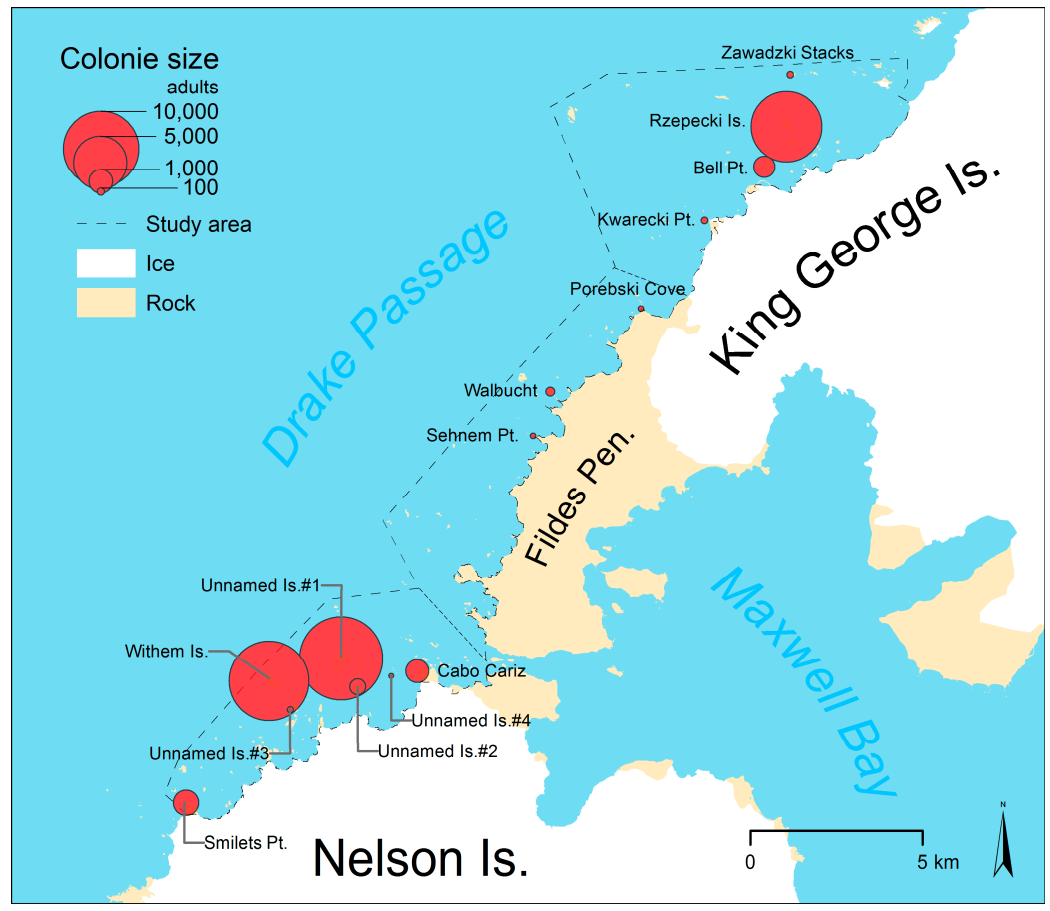

Figure 6. Size and location of chinstrap penguin colonies in the study area. 
One half $(n=7)$ of the identified colonies and $72 \%$ of the 25,597 adults were located in the southern subarea along the northwest coast of Nelson Island, including the largest colonies at Withem Island (11,007 adults) and on Unnamed Islands \#1 (11,959 adults in seven subcolonies) two kilometers east of Withem Island. Further north on the coast of the ice-free part of the Fildes Peninsula (central subarea) we found only three very small colonies (229 nests in total) on rock outcrops or islets. In the northern subarea, four colonies with 9791 adults were detected, the largest of these on the Rzepecki Islands (8703 adults in three subcolonies of similar size).

\subsection{Number of Occupied Nests}

In total, we estimated that there were $29,396 \pm 1722$ (estimate \pm margin of error at the $95 \%$ confidence level, standardized to one week after PoE) occupied nests in the study area. The estimated number of occupied nests for every colony and subcolony is given in Table 4 .

The ratio $r$ applied to the number of adults varies strongly with the image acquisition date (Figure 7). The GAM predicted ratios ranging from 0.78 to 0.86 . The first flights took place at a time with a strong declining ratio, while the last flights were in a period of a slowly increasing ratio.

For accuracy analysis, we counted a test group of penguins in a UAV orthomosaic of Unnamed Islands \#1, resulting in several 275 adults. With the ratio of 0.87 derived from the time-lapse cameras on Deception Island, we estimated 239 nests (margin of error: 11 nests), i.e., $7 \%$ more than a ground-based count of 223 nests.

The nest attrition from PoE to mean crèche in season 2016/17 at Vapour Col (Deception Island) derived from the time series of the time-lapse cameras was $18 \%$.

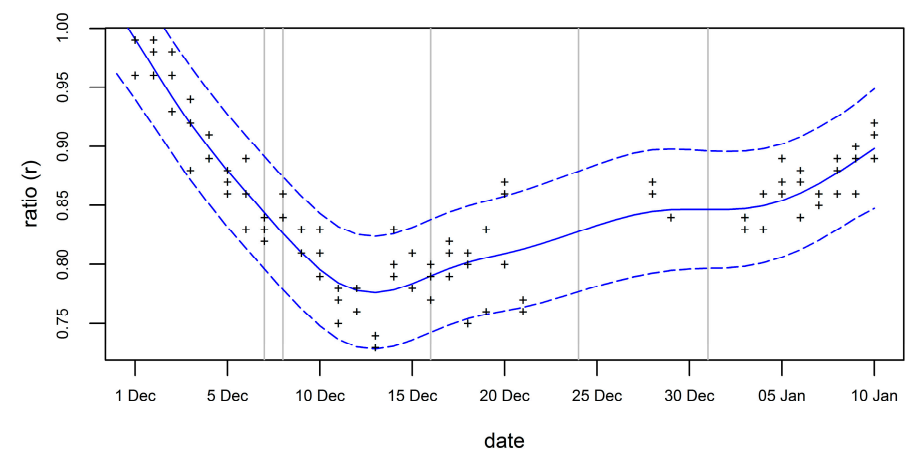

Figure 7. GAM-modeled variation of the ratio (peak number of nests divided by number of adults (blue solid line) and the 95\% prediction interval (blue dashed lines) in the chinstrap colony at Vapor Col (Deception Island) on the phenology corrected dates of the survey flights 2016/17 (grey vertical lines) derived from time series of counts.

\subsection{Long-Term Changes in Abundance and Distribution}

\subsubsection{Assignment of Colonies}

An overview of the assigned colonies is shown in Table 5. Shuford and Spear [16] did not describe the precise location of three colonies in the vicinity of Rip Point (site \#36 in Shuford and Spear [16]; see Figure 1). Nevertheless, one particularly large colony (15,000-20,000 adults) of these three can be matched with the colony on Unnamed Islands \#1 since Shuford and Spear [16] listed the only other similarly sized colony on Withem Island separately. They also did not define the precise location of a colony 3-4 km east of Harmony Point (site \#39 in Shuford and Spear [16]). Based on all available information, we inferred that this colony is located at Smilets Point.

We were unable to match the locations of the chinstrap colonies with 10,000 adults mentioned by Croxall and Kirkwood [60] and Zippel [61]. The description of the locations corresponds to Cabo Cariz, but an analysis of a UAV-derived orthomosaic and a digital surface model of the headland showed that the area suitable for breeding would not support a colony of that size. 
Table 5. Assignment of the colony location of colonies where the precise position was not given by previous surveys.

\begin{tabular}{ccc}
\hline Reference & $\begin{array}{c}\text { Description in Reference } \\
\text { (Translated to English) }\end{array}$ & Assigned Position \\
\hline Jablonski [15] & "Islands between Bell Island and & Kwarecki Pt." - Map \#41 \\
Shuford and Spear [16] & "15,000-20,000 adults" at No. 36 & Kwarecki Point \\
$\begin{array}{c}\text { Peter et al. [14] } \\
\text { Peter et al. [14] }\end{array}$ & "off Withem Island"/"Figure 8" & $\begin{array}{c}\text { Unnamed Islands \#1 } \\
\text { Unnamed Island \#2 } \\
\text { Withem Island }\end{array}$ \\
\hline
\end{tabular}

\subsubsection{Long-Term Change}

The long-term changes in abundance from previous counts are summarized in Table 6. It shows the comparison of the estimated breeding pair numbers of this study with the first available previous counts with sufficient accuracy for all colonies in the study area. The change for Unnamed Island \#2 was not estimated because of the high uncertainty of the previous counts. There were no previous counts for the colonies at Unnamed Islands \#3 and \#4. The detailed list is available in Supplementary Materials S2. The distribution of the changes is illustrated in Figure 8. In the following section, we will present the most substantial changes in detail.

In the northern subarea, the number of colonies has not changed since the survey of Jablonski [15] in austral summer 1980/81, although three subcolonies have been abandoned at Kwarecki Point and Zawadzki Stacks. The total number of occupied nests in the northern subarea decreased by about $24 \%$. However, the largest colony at Rzepecki Islands most likely increased by $11 \%$, while the smaller colonies decreased by up to $87 \%$.

In the central subarea, the total number of nests increased by $51 \%$ since the first complete census in 1984/85 [14]. However, the distribution has changed as the number of colonies decreased from six to three since season 1979/80 [13] and the remaining colonies showed an increase of their population by more than $33 \%$ since 1984/85 [14].

In the southern subarea, the estimated total population in season 1984/85 [14] was 70\% larger than in this study. However, due to the low accuracy of the previous studies, we do not have strong evidence of a decline. Nevertheless, at four colonies, the accuracy of the previous surveys allowed a more accurate estimation of the population change. The colonies at Unnamed Islands \#1 and Smilets Point decreased by about $45 \%$ since 1986/87 [16]. The population of the colony at Withem Island had probably also decreased since 1984 [14], but has remained stable since 2013/14 [20]. The comparison with Shuford and Spear [16] also revealed that the colony at Nancy Rock had been abandoned. The two colonies at Unnamed Island \#2 and \#3 that were newly discovered during this study were very small and may have been overlooked or found irrelevant by the authors of previous studies. We consider the establishment of new colonies during a period of general population decline in the area to be rather unlikely.

Table 6. Changes in breeding pair numbers with the first available previous counts in the study area. Values are based on adults (A), nests $(\mathrm{N})$ or chicks $(\mathrm{C})$ with an accuracy better than $\pm 5 \%(1), \pm 5-10 \%$ (2), $\pm 10-15 \%$ (3), $\pm 25-50 \%$ (4) or order of magnitude (5) [58].

\begin{tabular}{|c|c|c|c|c|c|c|}
\hline Sub-Area & Site & $\begin{array}{l}\text { Colony Size } \\
\text { [Nests] }\end{array}$ & $\begin{array}{c}\text { Base of } \\
\text { Counts and } \\
\text { Accuracy }\end{array}$ & $\begin{array}{c}\text { Change [\%] } \\
\text { (Uncertainty } \\
\text { Interval) }\end{array}$ & Season & Reference \\
\hline \multirow{4}{*}{ North } & Zawadzki Stacks & $\begin{array}{c}450 \\
68\end{array}$ & $\begin{array}{c}\mathrm{N} 2 \text { or } \mathrm{C} 2 \\
\mathrm{~A} 1\end{array}$ & $-85(-87,-82)$ & $\begin{array}{l}1980 / 81 \\
2016 / 17\end{array}$ & $\begin{array}{c}\text { Jablonski [15] } \\
\text { This study }\end{array}$ \\
\hline & Rzepecki Islands & $\begin{array}{l}6430 \\
7162\end{array}$ & $\begin{array}{c}\text { N2 or C2 } \\
\text { A1 }\end{array}$ & $12(-5,31)$ & $\begin{array}{l}1980 / 81 \\
2016 / 17\end{array}$ & $\begin{array}{c}\text { Jablonski [15] } \\
\text { This study }\end{array}$ \\
\hline & Bell Point & $\begin{array}{c}3274 \\
715\end{array}$ & $\begin{array}{c}\mathrm{N} 1-2 \text { or } \mathrm{C} 2 \\
\mathrm{~A} 1\end{array}$ & $-78(-81,-74)$ & $\begin{array}{l}1980 / 81 \\
2016 / 17\end{array}$ & $\begin{array}{c}\text { Jablonski [15] } \\
\text { This study }\end{array}$ \\
\hline & Kwarecki Point & $\begin{array}{l}800 \\
112\end{array}$ & $\begin{array}{c}\mathrm{N} 2 \text { or } \mathrm{C} 2 \\
\mathrm{~A} 1\end{array}$ & $-86(-88,-84)$ & $\begin{array}{l}1980 / 81 \\
2016 / 17\end{array}$ & $\begin{array}{c}\text { Jablonski [15] } \\
\text { This study }\end{array}$ \\
\hline
\end{tabular}


Table 6. Cont.

\begin{tabular}{|c|c|c|c|c|c|c|}
\hline Sub-Area & Site & $\begin{array}{l}\text { Colony Size } \\
\text { [Nests] }\end{array}$ & $\begin{array}{c}\text { Base of } \\
\text { Counts and } \\
\text { Accuracy }\end{array}$ & $\begin{array}{l}\text { Change [\%] } \\
\text { (Uncertainty } \\
\text { Interval) }\end{array}$ & Season & Reference \\
\hline \multirow{14}{*}{ Center } & \multirow{2}{*}{ Porebski Cove } & 32 & N1 & \multirow{2}{*}{$56(40,74)$} & $1980 / 81$ & Jablonski [15] \\
\hline & & 50 & $\mathrm{~A} 1$ & & 2016/17 & This study \\
\hline & \multirow{2}{*}{ Huashan Bandao } & $20-30$ & A3-4 & \multirow{2}{*}{ abandoned } & $1980 / 81$ & Jablonski [15] \\
\hline & & 0 & A1 & & 2016/17 & This study \\
\hline & \multirow{2}{*}{ Walbucht } & 39 & N1 & \multirow{2}{*}{$235(203,272)$} & $1984 / 85$ & Peter et al. [14] \\
\hline & & 131 & $\mathrm{~A} 1$ & & $2016 / 17$ & This study \\
\hline & \multirow{2}{*}{ Bothy Bay } & 3 & N1 & \multirow{2}{*}{ abandoned } & $1984 / 85$ & Peter et al. [14] \\
\hline & & 0 & A1 & & $2016 / 17$ & This study \\
\hline & \multirow{2}{*}{ Sehnem Point } & 36 & N1 & \multirow{2}{*}{$33(21,47)$} & $1984 / 85$ & Peter et al. [14] \\
\hline & & 48 & N1 & & 2016/17 & This study \\
\hline & \multirow{2}{*}{ Flat Top Peninsula } & 18 & N1 & \multirow{2}{*}{ abandoned } & $1980 / 81$ & Jablonski [15] \\
\hline & & 0 & A1 & & 2016/17 & This study \\
\hline & \multirow{2}{*}{ Exotic Point } & 25 & N1 & \multirow{2}{*}{ abandoned } & $1984 / 85$ & Peter et al. [14] \\
\hline & & 0 & A1 & & $2016 / 17$ & This study \\
\hline \multirow{12}{*}{ South } & \multirow{2}{*}{ Nancy Rock } & \multicolumn{2}{|c|}{ "covered with penguins" } & \multirow{2}{*}{ abandoned } & $1986 / 87$ & Shuford and \\
\hline & & 0 & $\mathrm{~A} 1$ & & 2016/17 & This study \\
\hline & \multirow{2}{*}{ Unnamed Islands \#1 } & 21,444 & $\mathrm{~A} 3$ & \multirow{2}{*}{$-56(-64,-45)$} & 1986/87 & $\begin{array}{l}\text { Shuford and } \\
\text { Spear }\end{array}$ \\
\hline & & 9376 & A1 & & $2016 / 17$ & This study \\
\hline & \multirow{2}{*}{ Cabo Cariz } & 1000 & N4 & \multirow{2}{*}{$-21(-50,68)$} & $1984 / 85$ & Peter et al. [14] \\
\hline & & 791 & A1 & & 2016/17 & This study \\
\hline & \multirow{2}{*}{ Unnamed Island \#2 } & $100-999$ & N5 & \multirow{2}{*}{ not defined } & $1984 / 85$ & Peter et al. [14] \\
\hline & & 383 & A1 & & 2016/17 & This study \\
\hline & \multirow{2}{*}{ Withem Islands } & 20,000 & N4 & \multirow{2}{*}{$-53(-70,0)$} & $1984 / 85$ & Peter et al. [14] \\
\hline & & 9483 & $\mathrm{~A} 1$ & & 2016/17 & This study \\
\hline & \multirow{2}{*}{ Smilets Point } & 2142 & $\mathrm{~A} 3$ & \multirow{2}{*}{$-54(-62,-43)$} & $1986 / 87$ & Shuford and \\
\hline & & 989 & $\mathrm{~A} 1$ & & $2016 / 17$ & This study \\
\hline
\end{tabular}

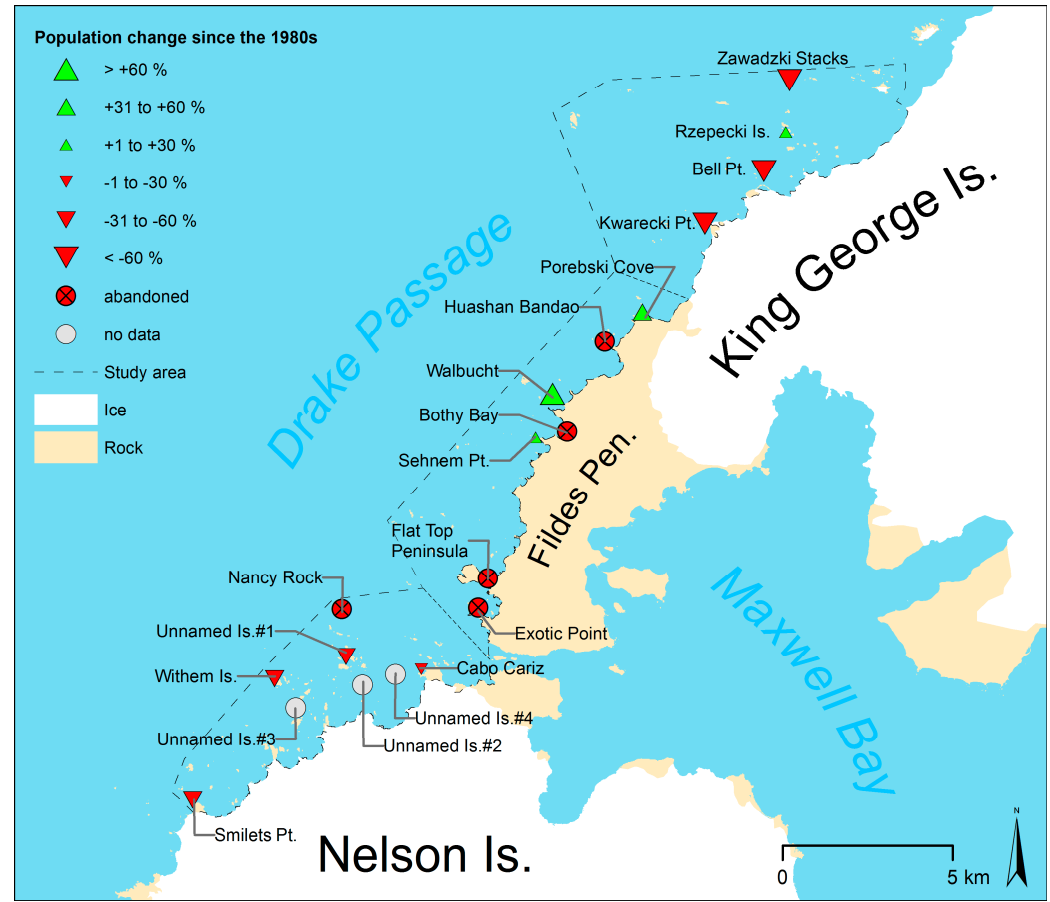

Figure 8. Estimated changes in the population of all chinstrap penguin colonies compared to previous counts of Jablonski [15] in season 1980/81, Peter et al. [14] in season 1984/85 and Shuford and Spear [16] in season 1986/87. 


\section{Discussion}

\subsection{Comparison with Earlier Survey Methods}

In comparison to the previous surveys conducted by boat in the region, fixed-wing UAVs provide some major advantages. The main advantage is that UAVs are more efficient. Two persons operating the UAV covered an area of up to $10 \mathrm{~km}^{2}$ in only five flights, enabling us to derive detailed numbers of adult individuals [33] for all penguin colonies in this area. In comparison, Shuford and Spear [16] needed a full day to cover the same area, but only achieved estimates of the number of adult penguins. In case of possible future monitoring campaigns, the number of flights and flight days necessary to map all 14 now known colonies could be reduced by two-thirds with the knowledge derived from this study. This means that only 26 islands, islets or headlands instead of the more than 300 of the whole study area would have to be covered.

UAV-based surveys can cover colonies that are not accessible or visible from a boat and are therefore unlikely to miss colonies located on one of the more than 300 islets in the area, including very small colonies of just four nests. For comparison, Shuford and Spear [16] reported only one colony between Fildes Peninsula and Sygit Point, while Jablonski [15] and this study found four colonies in the same area. The level of disturbance of the UAV used in the survey is also assumed to be lower than the disturbance produced by counting the penguins on the ground [20].

The major disadvantage of using UAVs is that nests are not clearly visible in the aerial images, and therefore adjustments have to be applied to the counts of individual adults. Nevertheless, it is still possible to derive accurate nest counts from the number of adults if flights are performed when only a few non-breeders are in the colony [28]. If flights were accomplished at a non-optimal time (number of adults and nests differs), an accurate estimation of the number of nests is still possible by using time-lapse cameras to calibrate correction factors $([44,47,62]$ or this study).

In this study, we used a battery-powered fixed-wing UAV for detecting chinstrap penguin colonies only. However, this type has proved to be suitable also for detecting other penguins species in the Antarctic such as Adélie (Pygoscelis adeliae), gentoo (Pygoscelis papua; see [20]) and possibly emperor penguins (Aptenodytes forsteri), as well as flying birds breeding on surface such as Antarctic shags (Phalacrocorax bransfieldensis) or southern giant petrels (Macronectes giganteus) [63]. Using automated counting methods [64] could reduce the time necessary for counting the individual penguins particularly for larger colonies e.g., [28].

\subsection{Comparison with Other UAV Types}

Battery-powered micro fixed-wing UAVs fill the gap between multicopter UAVs, which are most effective at the scale of individual colonies [20], and larger fixed-wing UAVs with internal combustion engines, which are able to cover numerous colonies in a single flight [6]. They combine the advantage of multicopter UAVs of being able to take off and land nearly anywhere with the longer range of large fixed-wing UAVs. The maximum flight range of $27 \mathrm{~km}$ achieved in this study under windy conditions (3-6 m/s wind speed) is still four to five times smaller than the range of the fixed-wing UAV with internal combustion engine used by Goetzendorf-Grabowski and Rodzewicz [32], but five times larger than the range of the multicopter UAV used by Mustafa et al. [20].

The long flight range, the ability to fly beyond the visual line of sight and outside the range of the onboard receivers also bears risks, since it is no longer possible to recognize and evade other aircraft. In this study, the risk of collision with manned aircraft was eliminated by accomplishing all flights below $120 \mathrm{~m}$ AGL, which is far below the minimum flight height of $610 \mathrm{~m}$ AGL for manned aircraft above bird concentrations and the coastline [65]. Our experience also underlines the importance of precise topographic elevation data for flights beyond the visual line of sight in particular with flight heights below $100 \mathrm{~m}$ AGL to ensure adequate image overlap and to prevent unintended ground contact. 
Another advantage of the low- and slow-flying battery-powered fixed-wing UAV are relatively small ground sampling distances (GSDs) of the derived orthomosaics, similar to the ones of mapping missions of the multicopter UAV used by Mustafa et al. [20] and about half the size of GSDs achieved by the larger fixed-wing UAV used by Zmarz et al. [6].

We measured a sound level of $40 \mathrm{~dB}$ for the Ninox UAV at a cruising speed of $12 \mathrm{~m} / \mathrm{s}$ and at $50 \mathrm{~m}$ AGL, which should not be an acoustic disturbance as it is below the ambient sound level of a chinstrap colony, which ranged from 60 to $84 \mathrm{~dB}$ at a distance of up to $90 \mathrm{~m}$ [29]. Nevertheless, possible effects of the shape of the Ninox-UAV at low flight heights due to its similarity to the shape of predators such as brown skuas (Catharacta antarctica lonnbergi) are unknown. Further experiments to reveal the possible disturbance level are necessary.

With its low weight and compact size, the UAV used in this study was as portable as a small multicopter e.g., [30]. This keeps the requirements for the logistics to and in Antarctica very low since the UAV can be transported on commercial flights as checked baggage, and the batteries as hand luggage. In contrast, larger UAVs that cannot be carried on commercial flights need to be transported by ship or cargo planes. The cost of the BORMATEC Ninox including equipment (approx. 2000€) is comparable to the cost of commercial off-the-shelf multicopters. Nevertheless, flight training and testing required months of preparation and should not be underestimated.

\subsection{Abundance and Distribution}

The results of this study enabled us to compile the first complete census of all colonies at northwestern Nelson Island since 1986/87 [16], of all colonies on Fildes Peninsula since 1989/90 [56], and of all colonies north of Fildes Peninsula since 1980/81 [15]. For eleven of the 14 colonies, we reported the most accurate counts of individuals ever made, and for two colonies, the first counts at all. Although miscounts are possible due to the confounding of penguins with rocks and cast shadows, the variation of the counts between the observers was relatively small (SD 1.9\%).

Since the counted number of adult penguins in the colonies has little significance for determining the colony population, we estimated the number of occupied nests for all colonies. For the colonies located in the southern subarea these are the most accurate numbers ever. A comparison of the accuracy of our counts with the ones from of Jablonski [15] is difficult, since the accuracy of population estimates reported in that study is unknown. It is not even clear if the published numbers of nests in that study were based on counts of nests or chicks since both methods have been used.

The method we used to estimate the number of nests is based on the assumption that the ratio of adults and nests in the colonies in the study area and in the colony at Deception Island is similar. Though it is known in Adélie penguins in East Antarctica [44,62] that there is a significant spatial and temporal variability in nest attendance, we found no studies in chinstrap penguins that analyzed these site-specific variations. Because we only had data from one colony, we could not account for possible site-specific variability. We considered variations during the day and intra-colony specific variation by using the data of three time points per day and two cameras in one colony. So if the site-specific variations (which are unknown) exceed the intra-day and intra-colony specific variation, the margins of error are potentially underestimated in this study. In consequence, the uncertainty intervals of the estimated population change would increase and therefore making clear and conclusive statements concerning possible changes more difficult. To account for this, we also published the raw counts of the number of adults giving other researchers the possibility to estimate the number of nests with more accurate methods in the future. An important step to improve the applied method would be the extension of the regional time-lapse camera network [52] in order to provide locally adapted estimations of the number of nests based on the raw counts of adults for the different species.

The evaluation of the method of the estimation of nest numbers with ground truth data from season 2017/18 revealed a deviation of $7 \%$. However, this number should be considered with caution, as the evaluation of a colony was done with only 275 adults, which is less than one percent of the total number of adults. Nevertheless, the results of the evaluation are consistent with the mean margin of 
error of $6 \%$ of the modeled results for $2016 / 17$. This result confirms the calculated uncertainty of our nest estimations of $5-10 \%$.

We also report for the first time the precise position and the extent of all colonies in the study area, which makes a comparison with potential future counts possible. Since we also publish the position of the subcolonies (Supplementary Material S3), future counts will be able to compare changes on a subcolony scale.

\subsection{Changes in Distribution and Abundance}

The recorded decrease in the population of six of the colonies and the decrease in the total population is consistent with observations in other chinstrap colonies at KGI [12,17,63,66,67], Nelson Island [68], Deception Island [10,11] and Livingston Island [69,70], where changes of the order of -25 to $-100 \%$ were found. Reasons for the decline of chinstrap populations may possibly be linked to regional effects of climate change such as changes in sea ice coverage and biological productivity [11], or to fishery [71], both of which may affect food availability.

It is remarkable how the changes vary between the individual colonies. As an example, four of the five colonies with a population of $>30$ nests in 1984/85 were abandoned completely, as was the small colony at Nancy Rock (100 to 999 nests) [58], which was the one furthest off the shore of all colonies at subarea South. The decline of the larger colonies manifests itself in abandoned subcolonies, as it was recorded at the Zawadzki Stacks and Kwarecki Point. Nevertheless, not all surveyed colonies declined. With Rzepecki Island, the biggest colony at the subarea North, we report only the second chinstrap penguin colony with a population of $>200$ nests in the Antarctic that most likely increased since the 1980s. The other is the colony at Narebski Point [72]. We also report three very small chinstrap penguin colonies ( $<200$ nests) that increased since the 1980s in addition to the one already known at Lions Rump [21]. All these colonies have in common that the surrounding colonies decreased drastically by around $80 \%$ (e.g., Bell Point) or were abandoned completely (e.g., Exotic Point). In the southern subarea, the data suggests that the largest colonies (Withem Island and Unnamed Islands \#1) did not increase. The cause of this irregular pattern of increasing colonies during a period of general decrease is unknown, and further studies are necessary.

Please note that the numbers for the comparisons are either based on estimates of adults [16] or on estimates of breeding pairs [14,15] with an accuracy of \pm 10 to $50 \%$. This should be kept in mind when interpreting the calculated change of the colonies in Table 6 . When comparing the change of the single colonies it should also be kept in mind that the previous counts are from different seasons.

When using the SCAR Composite Gazetteer of Antarctica [73] for geolocating the breeding sites, we noticed that these were often inaccurate or that in some cases there were even multiple locations for the same name, making a definite localization difficult [74]. The given text descriptions were often too vague to be useful.

All these findings are only possible as we were able to cover all colonies in a region and because there were historic counts available to compare these with. A more precise comparison with the previous studies was not possible, as the dates and/or the detailed methods of the counts were not published. We would like to point out the importance to publish the precise date and method when implementing censuses as well as an accuracy estimation to be able to compare these with other counts.

\section{Conclusions}

This study showed that it is feasible to survey penguin colonies with battery powered fixed-wing UAVs at a difficult to access geomorphological complex coastal area. It demonstrated the advantages of using a small and lightweight low-cost fixed-wing UAV with its low logistic demands and long flight range. We proved that it is possible to detect and map the precise location of previously unknown colonies, or colonies with inaccurate location information. The study revealed the importance of detailed elevation information for a survey with flight heights below $100 \mathrm{~m}$ AGL to ensure sufficiently high image overlap and to prevent unintended ground contact. Using the UAV orthomosaics, we were 
able to determine the most accurate abundance data ever published for most penguin colonies in the study area. The comparison with previous studies from the 1980s gave strong evidence for a general decline of the chinstrap penguin population in the study area although several colonies with a most likely increasing number of nests were found. Overall, we conclude that the developed method is able to efficiently perform a high-quality survey of chinstrap penguin colonies in a difficult to access area. Using these UAVs instead of the widely used multicopters enables scientist in the Antarctic to map colonies in a radius of at least $10 \mathrm{~km}$ around the research stations. This could significantly increase the number of colonies that get monitored and thus help to increase the understanding of the changes in the Antarctic ecosystem.

Supplementary Materials: The following are available online, Shape-File S1: complete UAV coverage, http://www.mdpi.com/2504-446X/3/2/39/s1, Table S2: detailed comparison with previous counts, http://www.mdpi. com/2504-446X/3/2/39/s2, Shape-File S3: penguin groups, http://www.mdpi.com/2504-446X/3/2/39/s3.

Author Contributions: Conceptualization, C.P.; methodology, C.P., O.M and Alexander Brenning (A.B.); software, C.P. and Alexander Brenning (A.B.); validation, C.P., O.M. and M.-C.R.; formal analysis, C.P. and Alexander Brenning (A.B.); investigation, C.P.; resources, C.P., Andres Barbosa (A.B.), H.-U.P. and M.-C.R.; data curation, C.P.; writing - original draft preparation, C.P.; writing—review and editing, all; visualization, C.P. and O.M.; supervision, C.P. and O.M.; project administration, O.M.; funding acquisition, O.M.

Funding: This research was commissioned by the German Federal Environment Agency and funded by the German Federal Ministry for the Environment, Nature Conservation and Nuclear Safety (UFOPLAN 371618 201 0). Data from Deception Island were obtained under the project CTM2015-64720-R funded by the Spanish Research Agency. The cameras at Deception Island were funded by the support of the CCAMLR (Commission for the Conservation of Antarctic Marine Living Resources) Ecosystem Monitoring Program Special Fund.

Acknowledgments: We thank the crew of the Bellingshausen Station (Russia) for accommodation and support during our expedition. We further like to thank Christina Braun, Hannes Grämer, Daniel Prowaznik and Raphael Ritter who conducted most of the ground surveys at the long and rough coast of Fildes Peninsula. We also want to thank the developer teams of ArduPilot, ExifTool, QGIS and R for developing and sharing their open-source software that we used in this study. We thank the crew of the Gabriel de Castilla Station (Spain) for support and hospitality, the RV/Hesperides for transportation to Deception Island and the Spanish Research Council Marine Technology Unit for logistic support.

Conflicts of Interest: The authors declare no conflict of interest.

\section{References}

1. Clarke, A.; Murphy, E.J.; Meredith, M.P.; King, J.C.; Peck, L.S.; Barnes, D.K.; Smith, R.C. Climate change and the marine ecosystem of the western Antarctic Peninsula. Philos. Trans. R. Soc. B Biol. Sci. 2007, 362, 149-166. [CrossRef]

2. Croxall, J.P.; Trathan, P.N.; Murphy, E.J. Environmental Change and Antarctic Seabird Populations. Science 2002, 297, 1510. [CrossRef] [PubMed]

3. Chabot, D.; Bird, D.M. Wildlife research and management methods in the 21st century: Where do unmanned aircraft fit in? J. Unmanned Veh. Syst. 2015, 3, 137-155. [CrossRef]

4. Hodgson, J.C.; Baylis, S.M.; Mott, R.; Herrod, A.; Clarke, R.H. Precision wildlife monitoring using unmanned aerial vehicles. Sci. Rep. 2016, 6, 22574. [CrossRef] [PubMed]

5. Rush, G.P.; Clarke, L.E.; Stone, M.; Wood, M.J. Can drones count gulls? Minimal disturbance and semiautomated image processing with an unmanned aerial vehicle for colony-nesting seabirds. Ecol. Evol. 2018, 8, 12322-12334. [CrossRef] [PubMed]

6. Zmarz, A.; Rodzewicz, M.; Dabski, M.; Karsznia, I.; Korczak-Abshire, M.; Chwedorzewska, K.J. Application of UAV BVLOS remote sensing data for multi-faceted analysis of Antarctic ecosystem. Remote Sens. Environ. 2018, 217, 375-388. [CrossRef]

7. Forcada, J.; Trathan, P.N.; Reid, K.; Murphy, E.J.; Croxall, J.P. Contrasting population changes in sympatric penguin species in association with climate warming. Glob. Chang. Biol. 2006, 12, 411-423. [CrossRef]

8. Trivelpiece, W.Z.; Trivelpiece, S.G.; Geupel, G.R.; Kjelmyr, J.; Volkman, N.J. Adélie and Chinstrap Penguins: Their Potential as Monitors of the Southern Ocean Marine Ecosystem. In Antarctic Ecosystems; Kerry, K.R., Hempel, G., Eds.; Springer: Berlin/Heidelberg, Germany, 1990; pp. 191-202. 
9. Lynch, H.J.; White, R.; Naveen, R.; Black, A.; Meixler, M.S.; Fagan, W.F. In stark contrast to widespread declines along the Scotia Arc, a survey of the South Sandwich Islands finds a robust seabird community. Polar Biol. 2016, 39, 1615-1625. [CrossRef]

10. Barbosa, A.; Benzal, J.; De León, A.; Moreno, J. Population decline of chinstrap penguins (Pygoscelis antarctica) on Deception Island, South Shetlands, Antarctica. Polar Biol. 2012, 35, 1453-1457. [CrossRef]

11. Naveen, R.; Lynch, H.J.; Forrest, S.; Mueller, T.; Polito, M. First direct, site-wide penguin survey at Deception Island, Antarctica, suggests significant declines in breeding chinstrap penguins. Polar Biol. 2012, 35, 1879-1888. [CrossRef]

12. Sander, M.; Balbão, T.C.; Polito, M.J.; Costa, E.S.; Carneiro, A.P.B. Recent decrease in chinstrap penguin (Pygoscelis antarctica) populations at two of Admiralty Bay's islets on King George Island, South Shetland Islands, Antarctica. Polar Biol. 2007, 30, 659-661. [CrossRef]

13. Bannasch, R.; Odening, K. Zoologische Untersuchungen im Gebiet der sowjetischen Antarktisstation "Bellingshausen". Geodätische Und Geophys. Veröffentlichungen 1981, Reihe I 8, 3-20.

14. Peter, H.-U.; Kaiser, M.; Gebauer, A. Untersuchungen an Vögeln und Robben auf King George Island (South Shetland Islands, Antarktis). Geodätische Und Geophys. Veröffentlichungen 1988, Reihe I 14, 1-127.

15. Jablonski, B. Distribution and numbers of penguins in the region of King George Island (South Shetland Islands) in the breeding season 1980/1981. Pol. Polar Res 1984, 5, 17-30.

16. Shuford, W.D.; Spear, L.B. Surveys of breeding Chinstrap Penguins in the South Shetland Islands, Antarctica. Br. Antarct. Surv. Bull. 1988, 81, 19-30.

17. Braun, C.; Esefeld, J.; Peter, H.-U. Monitoring the Consequences of Local Climate Change on the Natural Resources of the Ice-Free Regions of Maxwell Bay (King George Island, Antarctic); Texte 26/2017; German Environment Agency: Dessau-Roßlau, Germany, 2017; pp. 1-177.

18. Peter, H.-U.; Braun, C.; Janowski, S.; Nordt, A.; Stelter, M. The Current Environmental Situation and Proposals for the Management of the Fildes Peninsula Region; Texte 02/2013; Federal Environment Agency (Germany): Dessau-Roßlau, Germany, 2013; pp. 1-127.

19. Peter, H.-U.; Bueßer, C.; Mustafa, O.; Pfeifer, S. Risk Assessment for the Fildes Peninsula and Ardley Island, and Development of Management Plans for Their Designation as Specially Protected or Specially Managed Areas; Texte 20/08; Federal Environment Agency: Dessau-Roßlau, Germany, 2008; pp. 1-344.

20. Mustafa, O.; Esefeld, J.; Grämer, H.; Maercker, J.; Rümmler, M.-C.; Pfeifer, C. Monitoring Penguin Colonies in the Antarctic Using Remote Sensing Data; Texte 30/2017; German Environment Agency: Dessau-Roßlau, Germany, 2017; pp. 1-162.

21. Korczak-Abshire, M.; Węgrzyn, M.; Angiel, P.J.; Lisowska, M. Pygoscelid penguins breeding distribution and population trends at Lions Rump rookery, King George Island. Pol. Polar Res. 2013, 34, 87-99. [CrossRef]

22. Kokubun, N.; Lee, W.Y.; Kim, J.-H.; Takahashi, A. Chinstrap penguin foraging area associated with a seamount in Bransfield Strait, Antarctica. Polar Sci. 2015, 9, 393-400. [CrossRef]

23. Southwell, C.; Emmerson, L.; McKinlay, J.; Newbery, K.; Takahashi, A.; Kato, A.; Barbraud, C.; DeLord, K.; Weimerskirch, H. Spatially Extensive Standardized Surveys Reveal Widespread, Multi-Decadal Increase in East Antarctic Adélie Penguin Populations. PLoS ONE 2015, 10, e0139877. [CrossRef]

24. Lynch, H.J.; LaRue, M.A. Erratum: First global census of the Adélie Penguin. Auk 2015, 132, 562. [CrossRef]

25. Lynch, H.J.; Schwaller, M.R. Mapping the Abundance and Distribution of Adélie Penguins Using Landsat-7: First Steps towards an Integrated Multi-Sensor Pipeline for Tracking Populations at the Continental Scale. PLoS ONE 2014, 9, e113301. [CrossRef]

26. Schwaller, M.R.; Lynch, H.J.; Tarroux, A.; Prehn, B. A continent-wide search for Antarctic petrel breeding sites with satellite remote sensing. Remote Sens. Environ. 2018, 210, 444-451. [CrossRef]

27. Schwaller, M.R.; Southwell, C.J.; Emmerson, L.M. Continental-scale mapping of Adélie penguin colonies from Landsat imagery. Remote Sens. Environ. 2013, 139, 353-364. [CrossRef]

28. Borowicz, A.; McDowall, P.; Youngflesh, C.; Sayre-McCord, T.; Clucas, G.; Herman, R.; Forrest, S.; Rider, M.; Schwaller, M.; Hart, T.; et al. Multi-modal survey of Adélie penguin mega-colonies reveals the Danger Islands as a seabird hotspot. Sci. Rep. 2018, 8, 3926. [CrossRef]

29. Goebel, M.E.; Perryman, W.L.; Hinke, J.T.; Krause, D.J.; Hann, N.A.; Gardner, S.; LeRoi, D.J. A small unmanned aerial system for estimating abundance and size of Antarctic predators. Polar Biol. 2015, 38, 619-630. [CrossRef] 
30. Perryman, W.; Goebel, M.E.; Ash, N.; LeRoi, D.; Gardner, S. Small unmanned aerial systems for estimating abundance of krill-dependent predators: A feasibility study with preliminary results. AMLR 2014, 2011, 64-72.

31. Ratcliffe, N.; Guihen, D.; Robst, J.; Crofts, S.; Stanworth, A.; Enderlein, P. A protocol for the aerial survey of penguin colonies using UAVs. J. Unmanned Veh. Syst. 2015, 3, 95-101. [CrossRef]

32. Goetzendorf-Grabowski, T.; Rodzewicz, M. Design of UAV for photogrammetric mission in Antarctic area. Proc. Inst. Mech. Eng. Part G J. Aerosp. Eng. 2016. [CrossRef]

33. Hodgson, J.C.; Mott, R.; Baylis, S.M.; Pham, T.T.; Wotherspoon, S.; Kilpatrick, A.D.; Raja Segaran, R.; Reid, I.; Terauds, A.; Koh, L.P. Drones count wildlife more accurately and precisely than humans. Methods Ecol. Evol. 2018, 9, 1160-1167. [CrossRef]

34. Rümmler, M.-C.; Mustafa, O.; Maercker, J.; Peter, H.-U.; Esefeld, J. Sensitivity of Adélie and Gentoo penguins to various flight activities of a micro UAV. Polar Biol. 2018, 41, 2481-2493. [CrossRef]

35. Rümmler, M.-C.; Mustafa, O.; Maercker, J.; Peter, H.-U.; Esefeld, J. Measuring the influence of unmanned aerial vehicles on Adélie penguins. Polar Biol. 2016, 39, 1329-1334. [CrossRef]

36. Verfuss, U.K.; Aniceto, A.S.; Harris, D.V.; Gillespie, D.; Fielding, S.; Jiménez, G.; Johnston, P.; Sinclair, R.R.; Sivertsen, A.; Solbø, S.A.; et al. A review of unmanned vehicles for the detection and monitoring of marine fauna. Mar. Pollut. Bull. 2019, 140, 17-29. [CrossRef]

37. Barsch, D.; Blümel, W.-D. Untersuchungen zum Periglazial auf der König-Georg-Insel, Südshetlandinseln/Antarktika: Deutsche physiogeographische Forschungen in der Antarktis; Bericht über die Kampagne 1983/84. Ber. Zur Polarforsch. (Rep. Polar Res.) 1985, $24,76$.

38. Trujillo, A.P.; Thurman, H.V. Essentials of Oceanography, 11th ed.; Pearson: Boston, MA, USA, 2014; ISBN 978-0-321-81405-0.

39. Johnston, D.W. Unoccupied Aircraft Systems in Marine Science and Conservation. Annu. Rev. Mar. Sci. 2019, 11, 439-463. [CrossRef] [PubMed]

40. Dellaert, F.; Seitz, S.M.; Thorpe, C.E.; Thrun, S. Structure from motion without correspondence. In Proceedings of the IEEE Conference on Computer Vision and Pattern Recognition, Hilton Head Island, SC, USA, 15 June 2000; Volume 2, pp. 557-564.

41. Fretwell, P.T.; Phillips, R.A.; Brooke, M.d.L.; Fleming, A.H.; McArthur, A. Using the unique spectral signature of guano to identify unknown seabird colonies. Remote Sens. Environ. 2015, 156, 448-456. [CrossRef]

42. Rees, W.G.; Brown, J.A.; Fretwell, P.T.; Trathan, P.N. What colour is penguin guano? Antarct. Sci. 2017, 29, 417-425. [CrossRef]

43. Schwaller, M.R.; Olson, C.E.; Ma, Z.; Zhu, Z.; Dahmer, P. A remote sensing analysis of Adélie penguin rookeries. Remote Sens. Environ. 1989, 28, 199-206. [CrossRef]

44. Southwell, C.; McKinlay, J.; Low, M.; Wilson, D.; Newbery, K.; Lieser, J.L.; Emmerson, L. New methods and technologies for regional-scale abundance estimation of land-breeding marine animals: Application to Adélie penguin populations in East Antarctica. Polar Biol. 2013, 36, 843-856. [CrossRef]

45. Ainley, D.G. The Adélie Penguin: Bellwether of Climate Change; Ebrary Inc.: New York, NY, USA, 2002; ISBN 0-231-12306-X.

46. Lynch, H.J.; Fagan, W.F.; Naveen, R.; Trivelpiece, S.G.; Trivelpiece, W.Z. Timing of clutch initiation in Pygoscelis penguins on the Antarctic Peninsula: Towards an improved understanding of off-peak census correction factors. Ccamlr Sci. 2009, 16, 149-165.

47. McKinlay, J.; Southwell, C.; Trebilco, R. Integrating Count Effort by Seasonally Correcting Animal Population Estimates (ICESCAPE): A method for estimating abundance and its uncertainty from count data using Adélie penguins as a case study. Ccamlr Sci. 2010, 17, 213-227.

48. Southwell, C.; Emmerson, L. Remotely-operating camera network expands Antarctic seabird observations of key breeding parameters for ecosystem monitoring and management. J. Nat. Conserv. 2015, 23, 1-8. [CrossRef]

49. Müller-Schwarze, D. The Behavior of Penguins: Adapted to Ice and Tropics; SUNY Series in Animal Behavior; State University of New York Press: Albany, NY, USA, 1984; ISBN 978-0-87395-866-0.

50. Barbosa, A.; Moreno, J.; Potti, J.; Merino, S. Breeding group size, nest position and breeding success in the chinstrap penguin. Polar Biol. 1997, 18, 410-414. [CrossRef] 
51. CCAMLR CCAMLR Ecosystem Monitoring Program: Standard Methods; CCAMLR: Hobart, Australia, 2014.

52. Hinke, J.T.; Barbosa, A.; Emmerson, L.M.; Hart, T.; Juáres, M.A.; Korczak-Abshire, M.; Milinevsky, G.; Santos, M.; Trathan, P.N.; Watters, G.M.; et al. Estimating nest-level phenology and reproductive success of colonial seabirds using time-lapse cameras. Methods Ecol. Evol. 2018, 9, 1853-1863. [CrossRef]

53. Hastie, T.J.; Tibshirani, R.J. Generalized Additive Models, Volume 43 of Monographs on Statistics and Applied Probability; Chapman \& Hall: London, UK, 1990.

54. Wood, S.N. Generalized Additive Models: An Introduction with R; Chapman and Hall/CRC: Boca Raton, FL, USA, 2006.

55. Black, C.E. A comprehensive review of the phenology of Pygoscelis penguins. Polar Biol. 2016, 39, 405-432. [CrossRef]

56. Erfurt, J.; Grimm, H. Expeditionsbericht der 2. DDR-Antarktisexpedition, Überwinterungsteilnehmer an der 34. Sowjetischen Antarktisexpedition, Station "Bellingshausen" 1988-1990; Unpublished Expedition report; Akademie der Wissenschaften: Potsdam, Germany, 1990.

57. Mönke, R.; Bick, A. Fachlicher Bericht über die Teilnahme der DDR-Biologengruppe an der 31. Sowjetischen Antarktisexpedition (SAE), Station Bellingshausen, King George Island (Südshetland Inseln/Antarktis); Unpublished Expedition Report; Akademie der Wissenschaften: Potsdam, Germany, 1988.

58. Woehler, E.J. The Distribution and Abundance of Antarctic and Subantarctic Penguins. Polar Rec. 1993, 30, 66.

59. Mesas-Carrascosa, F.-J.; Notario García, M.D.; Meroño de Larriva, J.E.; García-Ferrer, A. An Analysis of the Influence of Flight Parameters in the Generation of Unmanned Aerial Vehicle (UAV) Orthomosaicks to Survey Archaeological Areas. Sensor 2016, 16, 1838. [CrossRef]

60. Croxall, J.P.; Kirkwood, E.D. The Distribution of Penguins on the Antarctic Peninsula and Islands of the Scotia Sea; British Antarctic Survey: Cambridge, UK, 1979.

61. Zippel, D. Teilbericht über die Wissenschaftlichen Ergebnisse Während der 30. SAE im Untersuchungsgebiet King George Island; Unpublished Expedition Report; Akademie der Wissenschaften: Potsdam, Germany, 1987.

62. Southwell, C.; Emmerson, L.; Newbery, K.; McKinlay, J.; Kerry, K.; Woehler, E.; Ensor, P. Re-Constructing Historical Adélie Penguin Abundance Estimates by Retrospectively Accounting for Detection Bias. PLoS ONE 2015, 10, e0123540. [CrossRef]

63. Korczak-Abshire, M.; Zmarz, A.; Rodzewicz, M.; Kycko, M.; Karsznia, I.; Chwedorzewska, K.J. Study of fauna population changes on Penguin Island and Turret Point Oasis (King George Island, Antarctica) using an unmanned aerial vehicle. Polar Biol. 2019, 42, 217-224. [CrossRef]

64. Grenzdörffer, G.J. UAS-based automatic bird count of a common gull colony. Int. Arch. Photogramm. Remote Sens. Spat. Inf. Sci. 2013, 1, W2. [CrossRef]

65. Harris, C.M. Aircraft operations near concentrations of birds in Antarctica: The development of practical guidelines. Biol. Conserv. 2005, 125, 309-322. [CrossRef]

66. Sander, M.; Carneiro, A.P.; Balbao, T.C.; Bays, S.R.; Costa, E.S.; Mascarello, N.E.; Oliva, T.D.; dos Santos, C.R. Status and Trends of Antarctic Seabirds at Admiralty Bay, King George Island. Polarforschung 2006, 75, 145-150.

67. Petry, M.V.; Valls, F.C.L.; Petersen, E.d.S.; Krüger, L.; Piuco, R.d.C.; dos Santos, C.R. Breeding sites and population of seabirds on Admiralty Bay, King George Island, Antarctica. Polar Biol. 2016, 39, 1343-1349. [CrossRef]

68. Silva, M.P.; Favero, M.; Casaux, R.; Baroni, A. The status of breeding birds at Harmony Point, Nelson Island, Antarctica in summer 1995/96. Mar. Ornithol. 1998, 26, 75-78.

69. Gil-Delgado, J.A.; González-Solís, J.; Barbosa, A. Populations of breeding birds in Byers Peninsula, Livingston Island, South Shetland Islands. Antarct. Sci. 2013, 25, 303-306. [CrossRef]

70. Lynch, H.J.; Naveen, R.; Fagan, W.F. Censuses of penguin, blue-eyed shag Phalacrocorax atriceps and southern giant petrel Macronectes giganteus populations on the Antarctic Peninsula, 2001-2007. Mar. Ornithol. 2008, 36, 83-97.

71. Ainley, D.G.; Blight, L.K. Ecological repercussions of historical fish extraction from the Southern Ocean. Fish Fish. 2009, 10, 13-38. [CrossRef]

72. ATCM Antarctic Specially Protected Area No 171 (Narębski Point, Barton Peninsula, King George Island): Revised Management Plan. In Proceedings of the Annex II, Brasilia, Brazil, 28 April-7 May 2014. 
73. Secretariat, S.C.A.R. Composite Gazetteer of Antarctica, Scientific Committee on Antarctic Research. GCMD Metadata. Available online: http://gcmd.nasa.gov/records/SCAR_Gazetteer.html (accessed on 25 June 2018).

74. Cervellati, R.; Ramorino, C.; Sievers, J.; Thomson, J.; Clarke, D. A composite gazetteer of Antarctica. Polar Rec. 2000, 36, 278. [CrossRef]

(C) 2019 by the authors. Licensee MDPI, Basel, Switzerland. This article is an open access article distributed under the terms and conditions of the Creative Commons Attribution (CC BY) license (http://creativecommons.org/licenses/by/4.0/). 